\title{
嫦娥一号探测器发现月球正面 “玉兔”火山
}

平劲松 ${ }^{(2)}$, 黄倩 ${ }^{(2)}$, 苏晓莉 ${ }^{(1)}$, 唐歌实 ${ }^{(2)}$, 舒嵘 ${ }^{(3)}$, 肖龙 ${ }^{(4)}$, 黄俊 ${ }^{(4)}$

(1) 中国科学院上海天文台, 上海 200030;

(2) 北京航天指挥控制中心飞行力学实验室, 北京 100094;

(3) 中国科学院上海技术物理研究所, 上海 200083;

(4) 中国地质大学(武汉)地球物理与空间信息学院, 武汉 430074

E-mail: pjs@shao.ac.cn

2009-06-05 收稿, 2009-08-13 接受

中国科学院百人计划和创新研究计划、上海市导航重点实验室、北京航天指挥控制中心飞行力学实验室专项研究基金、国家自然科学基金 面上项目(批准号: 10973031)和国家高技术研究发展计划(编号: 2008AA12A209, 2008AA12A210)资助

摘要 月面白天日照情况下, 高海拔、高反照率地区反射阳光产生的辐射状光线, 会对其周围海拔 低、地形变化缓慢、反照率低的地区带来显著的 “灯下黑”照明效应的影响, 甚至把这些地区的地貌 从光学波段 “隐藏” 起来. 利用嫦娥-1 绕月探测器激光测高得到的地形 DEM 模型, 对比重力探测 的历史结果, 在月球正面风暴洋西部(中心位于 $\left(14^{\circ} \mathrm{N}, 308^{\circ} \mathrm{E}\right)$ 处), 从“灯下黑”区域新认证了一个直 径约 $300 \mathrm{~km}$, 高度约 $2 \mathrm{~km}$ 的火山一一暂时称为“玉兔”山. 还修正了“玉兔”山以北 $300 \mathrm{~km}$ 左右的 关键词 嫦娥一号 月球地形 火山 玉兔 “桂树”火山三维地形. 该发现对研究月球正面演化过程有重要的参考价值.

\section{1 月球地形模型}

继 1994 年美国克莱门汀(Clementine)探测器成功地 获取了月球大部分地区的地形 ${ }^{[1,2]}$ 之后, 2007 年的两个新 的月球探测计划—日本“月女神” (SELENE/KAGUYA)和中国嫦娥一号(Chang'E-1, CE-1)对月球成功实 施探测. 媂娥一号探测器获得了 $120 \mathrm{~m}$ 分辨率的月面影 像, 岳宗玉等人 ${ }^{[3]}$ 利用影像数据探索了自动识别月面撞 击坑的方法. 两个新探测器还利用所搭载的激光高度计, 分别获得了月球全球三维地形模式. 这两个月球地形模 式分别称为 STM359_grid-02 $2^{[4]}$ 和 CLTM-s01 2 . 比较表明, 两个探测任务独立得到的月球地形模型在垂直方向彼此 符合.

利用频率域分析方法, 将月球全球地形模型与 月球重力场模型进行比对, 有助于对月球的二分性 及其内部结构的研究. 图 1 显示了嫦娥一号地形模型 CLTM-s01 分别与月球全球重力场模型 LP150Q ${ }^{[6]}$ 和
SGM90d ${ }^{[7]}$ 的相关特性. 月球的全球地形与重力在 100 300 km 中波长段上表现出强相关, 相关程度可 以达到 $90 \%$ 以上. 可以预计在更短的波长上, 地形与 重力两者之间应该表现出类似或者更强的相关性, 然而图中显示的结果并非如此. 考虑到全球地形精 度的一致性, 产生图 1 中高频率部分两者的弱相关现 象的主要原因, 是由重力场模型在高频部分的分辨 率和灵敏度较低而引起的.

绕月卫星的照相和激光测高科学探测数据实现了 人类对整个月球表面地形特征的分布和关系的研究. Zhao 等人 ${ }^{[8]}$ 利用月震数据同化技术, 对月球结构特征 开展了相应的研究. 利用得到的全月面地形图进行的 一个直接的分析, 是比对模型结果和已经确认的全球 地貌，搜索可能存在的新的月海、撞击坑或撞击盆地等 地形特征. 我们利用 CLTM-s01 模型展开得到的 $0.0625^{\circ} \times 0.0625^{\circ}$ 地形格网图 ${ }^{[5]}$, 将它与 ULCN2005 ${ }^{[9]}$ 以 及克莱门汀的影像数据(http://www.lpi.usra.edu/resource/

引用格式: 平劲松, 黄倩, 苏晓莉, 等. 嫦娥一号探测器发现月球正面 “玉免” 火山. 科学通报, 2009, 54: 3166 3169 Ping J S, Huang Q, Su X L, et al. Chang’ E-1 orbiter discovers a lunar nearside volcano: YUTU Mountain. Chinese Sci Bull, 2009, 54, doi: 10.1007/s11434009-0671-8 


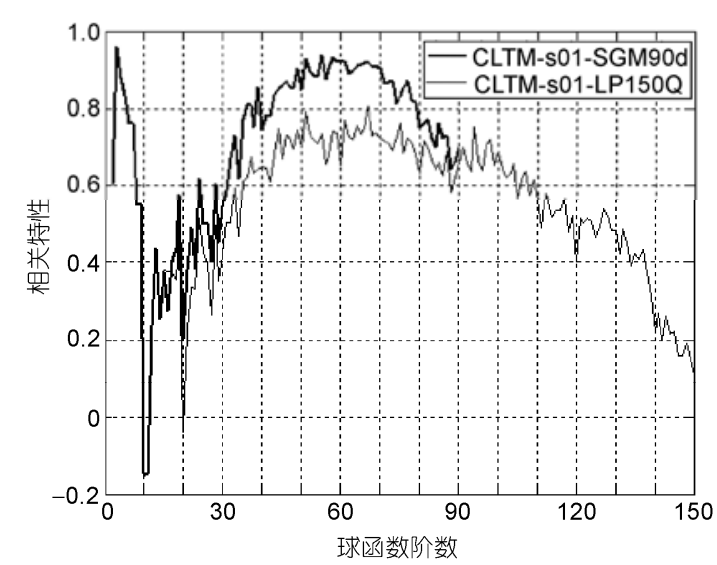

图 1 媂娥一号地形模型 CLTM-s01 与重力场模型的相关特性

mapcatalog/)作了极细致的比较, 一些中短波长上的 新特征已被发现 ${ }^{[10]}$. 在这些新特征中, 一个大的火山 高地已经得到证认, 并且在 STM359_grid-02 模型中也 可以清晰地看到.

\section{2 风暴洋中的“玉兔”火山}

风暴洋是月球上最大的月海, 位于月球正面的 西侧, 南北直径大于 $2500 \mathrm{~km}$, 面积约 400 万平方公 里. 它的四周有小型的月海, 如南面的云海、北侧的 雨海等. 风暴洋内还有许多引人注目的环形山, 如哥 白尼环形山、开普勒环形山等. 历史上多个无人月球 探测器在风暴洋进行软着陆探测, 包括月球 9 号、月 球 13 号、观测者 1 号和观测者 3 号. 阿波罗 12 号登
月舱也在风暴洋着陆, 宇航员皮特- 康拉德和艾 伦. 宾出舱活动, 并取回 $34.6 \mathrm{~kg}$ 月岩和月壤. 遥感探 测和采样分析表明, 和其他月海一样, 风暴洋由远古 火山喷发形成的玄武岩构成, 年龄约 32 40 亿年.

图 2(a)为 CLTM-s01 地形模型给出的风暴洋的西 部区域, 经度范围为 $300^{\circ} \sim 330^{\circ} \mathrm{E}$, 纬度范围为 $0^{\circ} \sim 30^{\circ} \mathrm{N}$. 图中清晰地显示出了南北两块高地. 北面 的高地中心位于 $\left(25^{\circ} \mathrm{N}, 310^{\circ} \mathrm{E}\right)$, 半径约 $250 \mathrm{~km}$ 、高度 约 $3 \mathrm{~km}$. 大多数月球探测得到的照相影像上可以看 到这个高地, 撞击坑 Aristarchus, Herodotus 以及月谷 Schroteri 均位于此区域. 南边黑实圆内的高地中心位 于 $\left(14^{\circ} \mathrm{N}, 308^{\circ} \mathrm{E}\right)$, 它距盆地底部的高度约为 $2 \mathrm{~km}$, 半 径约为 $300 \mathrm{~km}$. 给出正式的名字前, 我们称北部的 高地为“桂树”山(GUISHU Mountain), 南部的为“玉 兔”山(YUTU Mountain), 它们分别取自中国古代月 亮上关于广寒宫桂花树与玉兔的传说. 以上地名没 有出现在现有月面地貌的名称中, 我们正在向中国 和国际负责月面地名命名的权威机构申请上述命名. 日本“月女神”探测器得到的 STM359_grid-02 三维地 形图中也可以清晰地看到这两个高地.

然而, 在克莱门汀探测器和嫦娥一号探测器的 照相数据中, 在该区域都没有显示出任何异常的地 貌特征, 那里只是一片灰黑色的平坦之地. 克莱门汀 探测器由于卫星轨道和激光测高观测技术原因, 在

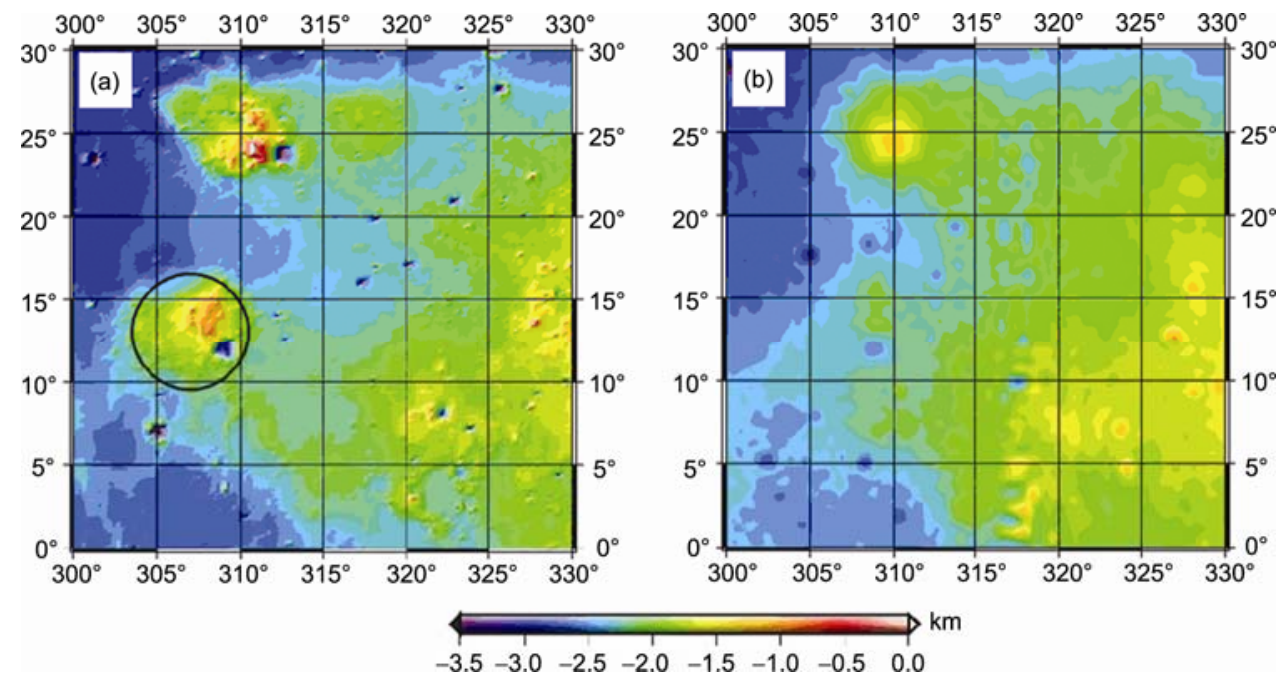

图 2 区域性月球地形图

(a) CLTM-s01 模型绘出; (b) ULCN2005 模型绘出 
这个区域也没有得到有效的观测结果. ULCN2005 给 出的 DEM 模型中, “玉兔”山区域仅仅显示出非常微 小的隆起. LPI 月球地形图在“桂树”山区域显示了复 杂的地貌特征, 如辐射状线、环形山、撞击坑、峡谷 以及边缘地貌. 但在玉兔山区域, 仅有撞击坑 Marius 和 Rima Marius 已被确认命名.

早期美国月球勘察者得到的 LP150Q 重力场模 型中，位于“玉兔”山处存在着一个约为 $250 \mathrm{mGal}(1$ $\left.\mathrm{Gal}=1 \mathrm{~cm} / \mathrm{s}^{2}\right)$ 的非常明显的正的重力异常, 而在嫦娥 一号探测器和“月女神”探测器发射前, 重力和地形 数据的不吻合, 让研究者猜测在这个区域地表下可 能存在有潜藏的高密度物质. 图 3 给出了图 2 地区的 立体地形和重力信息. 地形和重力的对应, 进一步印 证了“玉兔”山的存在.
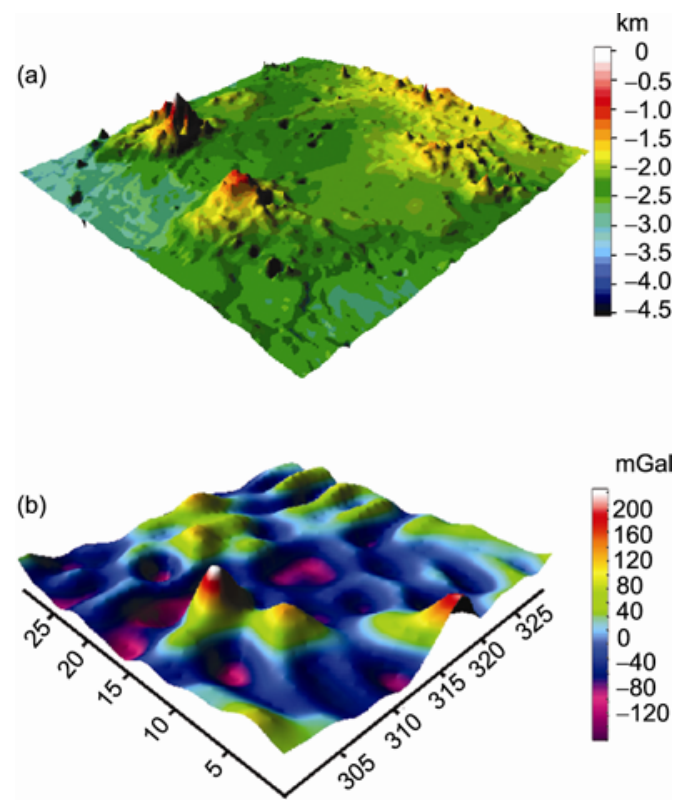

图 3 与图 2 相同区域的 CLTM-s01 模型三维地形(a)和 LP150Q 重力场异常 (b)

3 “玉兔”山被“隐藏” 原因的简单讨论

“玉兔”山没有被光学探测器探测到的原因并不 复杂. 地形数据表明, “玉兔”山西面和东面的山坡的 坡度(斜率)分别为 $1 \%$ 和 $2 \%$. 在早期的照相和图 4 所 示的嫦娥一号照相结果中可以看到，来自附近区域 的高反照率辐射撞击坑, Aristarchus 和 Kepler 撞击坑 的强照明淹没了整个“玉兔”山和部分的“桂树”山区 域. 月面白天“灯下黑”的照明影响在 20 世纪 70 年代 已经被注意到 ${ }^{[11]}$, 这种效应把辐射撞击坑附近的低

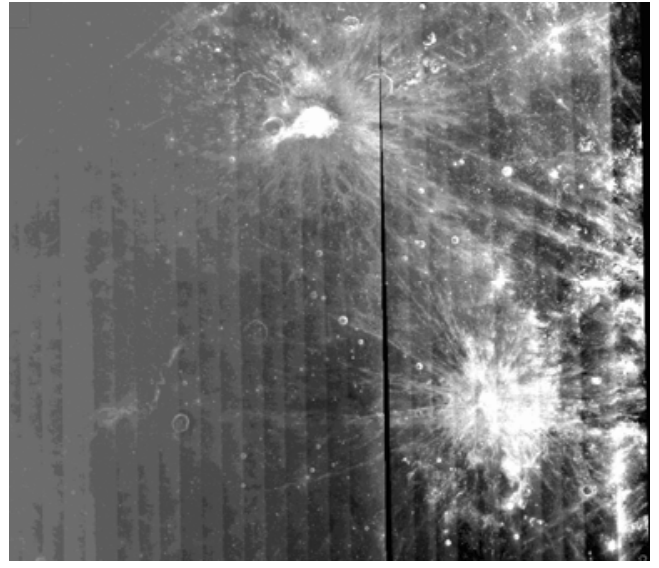

图 4 与图 2 同区域的嫦娥一号照相影像

反照率的缓变地形区域隐藏在了强光之后. 如此强 的照明效应, 使得历史上极轨探测器和低轨道倾角 探测器搭载的照相设备, 都未能绘出“玉兔”区域. 这 种效应也受到来自于东南面稍远一点的撞击坑 Copernicus 的影响. 由于这个原因，在历史上即使是 地球上的光学望远镜也未能鉴别出“玉兔”山.

“玉兔”山和“桂树”山位于风暴洋中由月海玄武 岩组成的火成岩区域. 由于月球没有经历过类似地 球的板块构造，其表面分布的高正地形只有两种成 因: 一是火山建造, 呈点状穹窡分布; 二是撞击坑周 边形成的环形高地或环形山 ${ }^{[12,13]}$. 显然, 这两个山型 地貌不可能是由撞击形成的. 早期的研究已经表明, 不同尺度的月面穹隆都是火山遗迹, 而且通常月面 火山的直径在 $180 \mathrm{~km}$ 以下 ${ }^{[14]}$. “玉兔”山和”桂树”山 的直径大于 $250 \mathrm{~km}$, 这样大规模的月面火山还是很 少见的. 在 玉兔”山的西南部, 弯曲的熔岩流地貌出 现在撞击坑 Reiner 和山周围的一些其他地方. 在该 区域地形与重力强的正负强相关, 表明高密度幔物 质和低密度壳物质在该地区交替存在，暗示曾经发 生过地幔物质大量涌上涌出的地质过程, 支持了火 山遗迹的观点. 另外, “桂树”山与 “玉兔” 山类似的 地貌、重力以及光学特征, 也预示它们相同的起源和 演化历史. 初步估计, 它们的地质年代位于前雨海纪 和后风暴洋纪之间. “玉兔”山区域较低的撞击坑密度 表明, 它可能产生于前雨海的后期. 该区域的地形地 貌比目前人类对它的认识要复杂得多，日本“月女 神”探测以及未来嫦娥月球探测计划获取的更高空间 分辨率的数据, 将有益于对该区域的地质演化过程 做进一步研究和解释. 


\section{参考文献}

1 Zuber M T, Smith D E, Lemoine F G, et al. The shape and internal structure of the moon from the clementine mission. Science, 1994 , 266: $1839-1843$ [doi]

2 Smith D E, Zuber M T, Neumann G A, et al. Topography of the moon from the Clementine lidar. J Geophys Res, 1997, 102: 15911611 [doi]

3 岳宗玉，刘建忠，吴涂国．应用面向对象分类方法对月球撞击坑进行自动识别．科学通报, 2008, 53: 2809一2813

4 Araki H, Tazawa S, Noda H, et al. Lunar global shape and polar topography derived from Kaguya-LALT laser altimetry. Science, 2009, 323: $897-900$

5 平劲松, 黄倩, 漂建国, 等. 基于嫦娥一号卫星激光测高观测的月球地形模型 CLTM-s01. 中国科学 G 辑: 物理学 力学 天 文学, 2008, 38: 1601-1612

6 Konopliv A S, Asmar S W, Yuan D N. Recent gravity models as a result of the lunar prospector mission. Icarus, 2001, 150: 1$18 \underline{\text { doi }]}$

7 Namiki N, Iwata T, Matsumoto K, et al. Farside gravity field of the moon from four-way doppler measurements of SELENE (Kaguya). Science, 2009, 323: 900-905[doi]

8 Zhao D, Lei J, Liu L. Seismic tomography of the Moon. Chinese Sci Bull, 2008, 53: 3897-3907[doi]

9 Archinal B A, Rosiek M R, Kirk R L, et al. The unified lunar control network 2005. U.S. Geological Survey Open-File Report, 2006, Version 1.0, 2006-1367

10 黄倩, 平劲松, 苏晓莉, 等. 嫦娥一号 CLTM-s01 模型揭示和证认的月球地形新特征. 中国科学 G 辑: 物理学 力学 天文学, 2009, 39: 1362-1370

11 Wu S S C. The effect of illumination on the precision of photogrammetric measurements using Apollo metric camera photographs. In: American Society of Photogrammetry and American Congress on Surveying and Mapping, Fall Convention, Phoenix, Ariz., 1975. Proceedings (A76-38501 19-43) Falls Church, Va., American Society of Photogrammetry, 1976. 99-118

12 肖龙, 何琦, 黄定华, 等. 太阳系天体的火山作用及其比较行星学意义. 地质科技情报, 2008, 27: 20-30

13 肖龙, Greeley R, 曾佐勋, 等. 比较行星地质学的研究方法、现状和展望. 地质科技情报, 2008, 27: 1-13

14 Elston W E. Evidence for lunar volcano-tectonic features. J Geophys Res, 1971, 76: 5690 — 5702 [doi] 